\title{
Scientometric analyzing the output of researchers and organizations on COVID-19 for better conducting the scientific efforts: with a glance to endocrinology
}

\author{
Rasha Atlasi $^{1,2} \cdot$ Abdolreza Noroozi Chakoli $^{3}$ (D) Aboozar Ramezani ${ }^{4} \cdot$ Ozra Tabatabaei-Malazy ${ }^{5,6} \cdot$ Bagher Larijani $^{6}$
}

Received: 24 November 2020 / Accepted: 25 December 2020 / Published online: 29 January 2021

(C) Springer Nature Switzerland AG 2021

\begin{abstract}
Purpose As COVID-19 spreads rapidly and could affect the people and also lead to their death, especially individuals with underlying diseases, such as diabetes, the research community is also active in publishing novel research about it. Analyzing scientific outputs in this topic can represent an overview of publications. For this purpose, this study was conducted to determine status of publishing research works related to COVID-19 and analyzing the all documents published and indexed in Web of Science database and illustrate the co-occurrence and co-authority of hot papers in this documents.

Methodology Our search strategy was based on using the related key terms including COVID-19, coronavirus, SARS2, etc., to find out all the published scientific works related to coronavirus disease indexed in web of science (WoS) in 2020. We then extracted the all hot papers and especially hot papers in endocrinology category and analyzed them. The data saved and imported in VOSviewer and ScientoPy programs for analysis and illustration of our data. We have shown our analysis in the tables, figures and maps.

Results Totally, 56,402 records and 309 hot papers were retrieved. 3 of these hot papers were in endocrinology category. The most common type of publication was original papers followed by editorial papers in the second rank. The country with the most published documents was the USA followed by China. The journals of "British Medical Journal" and "Journal of Medical Virology" were ranked as the first and second sources, respectively. The "Harvard University" was the top organization with high proportion of scientific publications and "the Lancet" was the top-ranked journal that published highly-cited papers.

Conclusion The literature on COVID-19 is increasing with a high and fast growth. In this regard, there is a need to evaluate these publications once in a while and their results should be published to use this information for more effective management of future research works with emphasizes on the gaps of researches and more citable documents and allocation of budgets on more needed research and don't carry out the duplicates research. This would be helpful for prevention, control, and treatment of COVID-19 that is now among the most common topics in the world.
\end{abstract}

Keywords Scientometrics $\cdot$ Coronavirus $\cdot$ COVID-19 $\cdot$ Scientific production

Abdolreza Noroozi Chakoli

Noroozi@shahed.ac.ir; http://ref.shahed.ac.ir/noroozi_en

Rasha Atlasi

Rashaatlasi@gmail.com

Aboozar Ramezani

Ramezani-a@alummus.tums.ac.ir

Ozra Tabatabaei-Malazy

Tabatabaeiml@sina.tums.ac.ir

Bagher Larijani

Emrc@tums.ac.ir

1 Department of Medical Library \& Information Science, School of Allied Medical Sciences, Tehran University of Medical Sciences, Tehran, Iran
2 Evidence based Practice Research Center, Endocrinology and Metabolism Clinical Sciences Institute, Tehran University of Medical Sciences, Tehran, Iran

3 Department of Information Science and Knowledge Studies and Scientometrics, Faculty of Humanities Sciences Shahed University Persian Gulf Highway Tehran 3319118651 Iran

4 Tehran University of Medical Sciences, Tehran, Iran

5 Non-Communicable Diseases Research Center, Endocrinology and Metabolism Population Sciences Institute, Tehran University of Medical Sciences, Tehran, Iran

6 Endocrinology and Metabolism Research Center, Endocrinology and Metabolism Clinical Sciences Institute, Tehran University of Medical Sciences, Tehran, Iran 


\section{Introduction}

A novel type of coronavirus, identified as COVID-19, appeared in Wuhan, China, in late 2019 and continued to spread in 2020 [1-3]. On March 11th, 2020, the world health organization (WHO) declared coronavirus disease 2019 (COVID-19) a pandemic [4]. The pandemic was introduced as pneumonia of unknown causes in China [3,5] . This virus was initially called as "novel coronavirus 2019" by the WHO, then it was renamed as "severe acute respiratory syndrome coronavirus 2" (SARS-CoV-2) by the international committee of the coronavirus study group (CSG), and now, WHO has called the disease as "coronavirus disease 2019" (COVID-19) [6].

This pandemic of disease surprised the whole world by its contagiousness and its high speed of diffusion and also its violence in terms of deaths [7]. This is of great importance for the people with weak immune systems or underlying diseases, such as individuals with diabetes mellitus, hypertension,or severe obesity as they are more exposed to be infected and getting sick by coronavirus and they are at a higher risk for complications and death from this disease [8-10].

These diseases have a high prevalence and for instance, diabetes that is a chronic and metabolic disease leads over time to serious damage to the diabetic patients such as their heart, blood vessels, eyes, kidneys and nerves. The most common of this disease is the type 2 diabetes and the prevalence of this type of diabetes also has risen dramatically in all countries in the past three decades and usually is in adults that are more infected with coronavirus [11].

Now, the COVID-19 pandemic has put unprecedented pressures on healthcare systems worldwide, as on August 23rd 2020, 23,025,622 confirmed cases of COVID-19 were reported as well as 800,420 deaths by WHO [12].

Regarding the urgent need for evidence to support clinical and public health decisions and manage this disease [13], researchers have begun summarizing and analyzing the published literature to aggregate the current evidence [14-16] and bibliometric analyses [16-20]. Bibliometric analyses and studies have attempted to show an overview of the COVID-19 as a possible research landscape thus, more studies are needed continually to provide more knowledge about this new topic [21].

In the last few months, enormous efforts have been made in knowledge production and many kinds of research have been carried out about this virus and pandemic disease. In this regard, many other studies have attempted to analyze these research works and publications based on scientometric and bibliometric approaches of study therefore, a comprehensive analysis is needed to find out the research gaps and to help guiding an agenda for further studies [22].

\section{Related works}

In this regard, De Felice and Polimeni carried out a study by searching in the Scopus database and used the term of "COVID-19" as research criterion. The literature search was refined to include the documents published between December 1, 2019 and April 20, 2020. A machine learning bibliometric methodology was applied to evaluate distribution of each factor in this study and the bibliometrix $\mathrm{R}$ package was used for this purpose. The results showed an exponential increase in the COVID-19 publications in the last months and China had published the majority of papers followed by the USA, UK, and Italy., there were a greater collaboration between highly contributing authors and institutions. In terms of journal ranking, the "BMJ" had published the greatest number of papers $(n=129)$ and "the Lancet" had the most citations $(n=1439)$ [23].

In another study, Liu et al., searched the PubMed and Embase databases for medical literature on COVID-19 between January 1 and March 24, 2020 and characterized growth of the early COVID-19 medical literature using evidence maps and bibliometric analyses and elicited cross-sectional and longitudinal trends and then, systematically identified the gaps. They revealed that the early COVID-19 medical literature has been originated primarily from Asia and has focused mainly on clinical features and diagnosis of the disease and many areas of potential research have remained underexplored, such as mental health. A few number of papers involved research collaboration at the international level $(24.7 \%)$. They concluded that although, COVID-19 research has generated a large volume of publications but there are still knowledge gaps to be addressed and also there exist areas to be improved for the global research community [21].

Chahrour et al., conducted a study to explore activity and trend of COVID-19 research worldwide since its outbreak in December 2019. The PubMed and WHO databases were searched for publications about COVID19 from December 2019 to March 18, 2020. Only relevant observational and interventional studies were included in this study. Their results showed that 564 publications met their inclusion criteria and these papers came from 39 different countries constituting 24\% of all the affected countries. China had published the greatest number of papers with 377 publications (67\%). Asian countries had the highest research activity with 434 original publications (77\%) [18].

In another study, Tran et al., aimed to explore the current research foci and their country variations regarding the levels of income and COVID-19 transmission features. A textual analysis was performed on 5780 publications extracted from the WoS, Medline, and Scopus databases published until April 23, 2020. The latent 
Dirichlet allocation (LDA) model was used for topic modeling and regression analysis was conducted for evaluating country variations in the research foci. Results showed that publications were mainly contributed by the USA, China, and European countries. Guidelines for emergency care and surgical and viral pathogenesis, and global responses in the COVID-19 pandemic were among the most common topics. They also found a variation in the research approaches in the countries with different income and transmission levels [22].

Dehghanbanadaki et al., in their study also searched about the COVID-19 documents indexed in the Scopus database from December 1, 2019 to April 1, 2020, by evaluating their bibliometric characteristics including document type, H-index, top cited documents, the most productive countries, institutions, and journals, international collaboration, and the most frequent terms and keywords. In total, 923 documents on COVID-19 were retrieved. Half of the retrieved documents were original papers and the remaining ones included 151 letters, 134 notes, 116 editorials, 75 reviews, 14 errata, 14 short surveys, and 1 data paper. In terms of countries, China was ranked the first with 348 documents, followed by the USA $(n=160)$. Regarding journals, the journals of Lancet and BMJ (Clinical Research Edition) published the most documents (each with 74 documents) and in ranking of institutions, the University of Hong Kong and Huazhong University of Science and Technology were ranked the first [19].

Studies done on COVID-19 have major importance for containment and prevention of the disease or treatment of the patients [24]. Reports and research from countries would delineate risk factors, clinical features as well as treatment strategies for the patients with COVID-19 [25]. However, studies only focused on a specific aspect of COVID-19, as well as review papers are unable to capture a comprehensive picture of global COVID-19 research. One solution to address these limitations is performing bibliometric analysis. Using systematically quantitative analyses for large number of publications, quantifying growth of research productivity, determining the most prolific countries and institutions, and also development of research contents seem to be useful and necessary $[17,18,26]$.

For this purpose, the present study was conducted to evaluate the scientific output of researchers and their affiliated organizations and to determine status of publishing research related to coronavirus and the research area, as well as the journals, countries, or authors with the most published papers, and types of publications. Also, the map and networks of important characteristics related to highly cited papers retrieved in this research were also illustrated. In this regard, in this paper, it was attempted to analyze all the scientific outputs related to the coronavirus and COVID-19, until now (November $12,2020)$ indexed in the WoS database in order to find out the last updated results according to scientometric analysis of the research published in the last months, which are producing more and more and to extract the all hot papers of them and identifying especially the hot papers in the endocrinology field to find out the details and characteristics of these top works with the highest citations. Distinguishing the gaps, identifying the last information about status of the research related to this disease, and providing new information for researchers and policy-makers are among useful and applicable measures. Also, this helps to manage allocation of budget in institutions and helps scientists to focus on new research works in various aspects that are needed to have access to new findings in relation to control and treatment of this disease.

\section{Methodology}

In this study, our search strategy was carried out to find out all the research works and scientific publications related to coronavirus disease and COVID-19 published and indexed in the WoS database over the last months since outbreak of this disease around the world. Our search was conducted and the results were analyzed on November 12, 2020 and search date was limited to the year of 2020 . No other limits were applied in this search.

The search strategy was as follows:

TS $=($ COVID-19 OR COVID-19 OR SARS-CoV-2 OR coronavirus* OR Deltacoronavirus* OR Alphacoronavirus OR Betacoronavirus OR Gammacoronavirus OR (corona AND Virus*) OR 2019-nCoV OR SARS2 OR “SARS 2").

Totally, 56,402 records were found to be indexed in the WoS database in this timespan and all of these results were analyzed using the tools for analysis of results in the WoS database and excel program to provide informative tables,

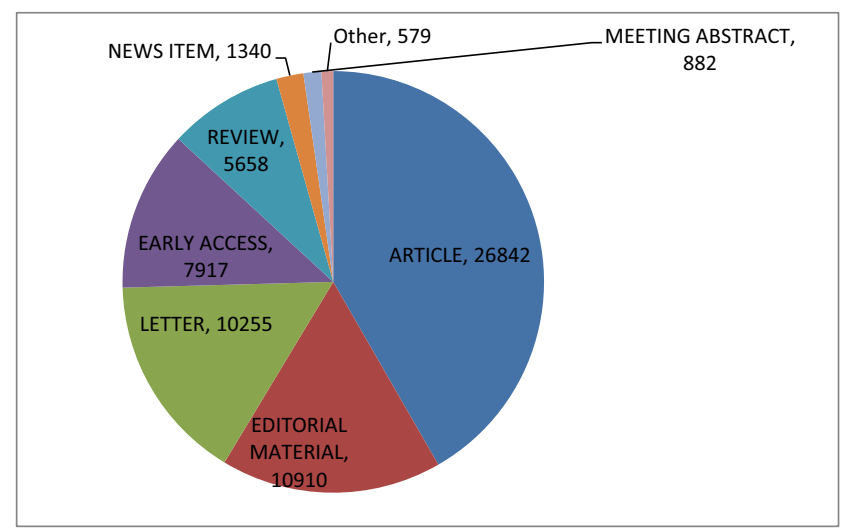

Fig. 1 Document types for the retrieved 56, 402 publications 
Table 1 The top ten journals published documents in the field

\begin{tabular}{|c|c|c|c|c|}
\hline NO & Source Titles & IF & $\begin{array}{l}\text { Record } \\
\text { Count }\end{array}$ & $\begin{array}{l}\% \text { of } \\
56,402\end{array}$ \\
\hline 1 & British Medical Journal (BMJ) & 17.215 & 1068 & $1.894 \%$ \\
\hline 2 & Journal of Medical Virology & 2.021 & 703 & $1.246 \%$ \\
\hline 3 & $\begin{array}{l}\text { International Journal of } \\
\text { Environmental Research And } \\
\text { Public Health }\end{array}$ & 2.849 & 437 & $0.775 \%$ \\
\hline 4 & Cureus & - & 425 & $0.754 \%$ \\
\hline 5 & Lancet & 60.39 & 411 & $0.729 \%$ \\
\hline 6 & Plos One & 2.74 & 304 & $0.539 \%$ \\
\hline 7 & $\begin{array}{l}\text { Journal of The American Medical } \\
\text { Association (JAMA) }\end{array}$ & 45.54 & 285 & $0.505 \%$ \\
\hline 8 & Nature & 42.779 & 283 & $0.502 \%$ \\
\hline 9 & $\begin{array}{l}\text { International Journal of Infectious } \\
\text { Diseases }\end{array}$ & 3.202 & 273 & $0.484 \%$ \\
\hline 10 & New England Journal of Medicine & 74.699 & 268 & 0.475 \\
\hline
\end{tabular}

Legend: IF: Impact Factor.

charts, and diagrams. For designing the networks and maps from 309 hot papers retrieved in this study that obtained from the hot papers filter in WoS results page, the VOSviewer software version1.6.15 released on April 1, 2020 and ScientoPy software v2.0.3 were used.

VOSviewer software is a common and very useful software program for illustration of network and density of cooccurrence and co-authorship of authors, organizations, countries and keywords and other items of documents. We used this program to network visualizations of authors, organizations and countries contributed to producing the hot papers related to COVID-19 in WoS database. And we also use the ScientoPy software to better showing the keywords occurrence and in another view.

For identifying the hot papers in the endocrinology filed we also used the web of science categories and fond out 3 hot papers in the endocrinology category and explained details of them. Finally, these all results were illustrated in the figures, networks, maps and tables.

\section{Results}

According to our results, most of the documents published for this topic in $2020(n=56,347)$ and $2021(n=55)$ in this database were original papers $(42 \%, 26,842$ records) and editorials (17\%, 10,910 records), followed by other types of documents including data paper $(n=44)$, book review $(n=34)$, proceedings paper $(n=18)$, biographical item $(n=7)$, and so on. Fig. 1shows the related results (Fig. 1).

Table 1 presents the top 10 journals that have published these documents. As shown in this table, British Medical Journal (BMJ) with 1068 records and Journal of Medical Virology with 703 records were the high -ranked journals with more proportion of documents in the field (Table 1).

According to the top 10 research areas extracted from these publications, the first area was related to general internal medicine $(n=8168)$ and the second area was related to public environmental and occupational health $(n=4119)$. The third area was also related to infectious diseases with 3014 items (Fig. 2).

The top 10 organizations attempted to work and publish scientific evidence and outputs were also determined and the results showed that the University of London (1793 documents), Harvard University (1774 documents), University of California (1595 documents), and Harvard Medical School (598 documents) were ranked as the first to fourth organizations in ranking related to institutions published documents about coronavirus(Table 2).

Among the top 10 countries that worked and published papers and other scientific publications about this disease, the USA was in the first place with 15, 860 documents and China and Italy had the second and third ranks in this list with 7328 and 5956 documents, respectively (Table 3).
Fig. 2. The top ten research areas of publications

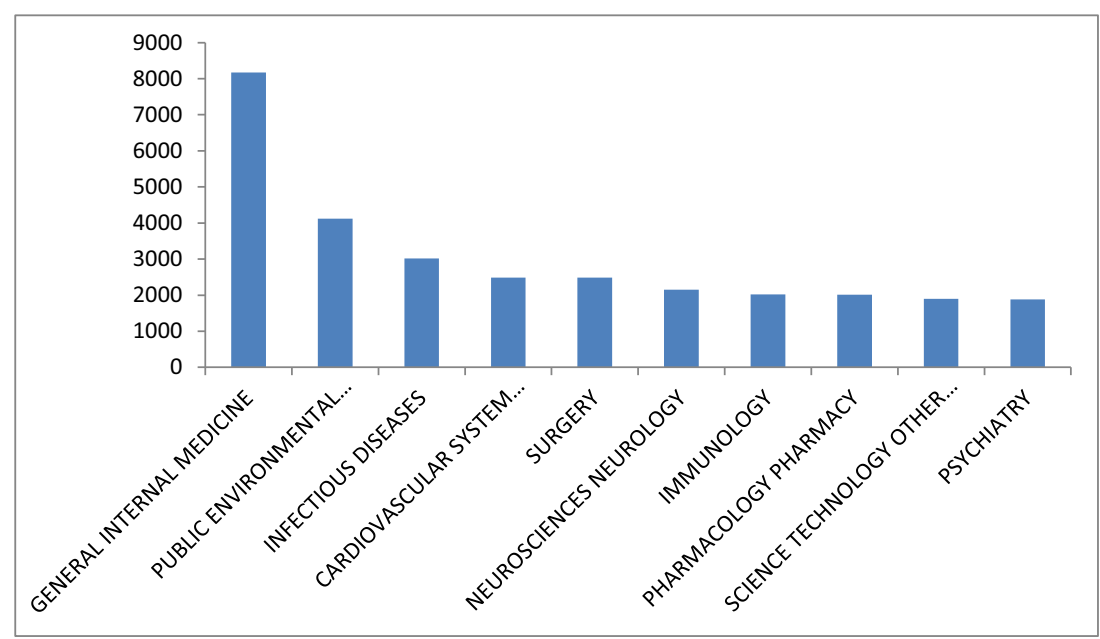


Table 2 The top ten organizations contributed in publishing the documents

\begin{tabular}{|c|c|c|c|c|}
\hline NO & Organizations-Enhanced & Country & $\begin{array}{l}\text { Record } \\
\text { Count }\end{array}$ & $\begin{array}{l}\% \text { of } \\
56,402\end{array}$ \\
\hline 1 & Harvard University & USA & 1649 & $2.924 \%$ \\
\hline 2 & University of London & England & 1644 & $2.915 \%$ \\
\hline 3 & University of California System & USA & 1253 & $2.222 \%$ \\
\hline 4 & Harvard Medical School & USA & 1006 & $1.784 \%$ \\
\hline 5 & $\begin{array}{l}\text { Huazhong University Of Science } \\
\text { Technology }\end{array}$ & China & 931 & $1.651 \%$ \\
\hline 6 & $\begin{array}{l}\text { Institut National de la Sante et de la } \\
\text { Recherche Medicale Inserm }\end{array}$ & France & 770 & $1.365 \%$ \\
\hline 7 & University College London & England & 737 & $1.307 \%$ \\
\hline 8 & University of Toronto & Canada & 719 & $1.275 \%$ \\
\hline 9 & $\begin{array}{l}\text { Assistance Publique Hopitaux Paris } \\
\text { Aphp }\end{array}$ & France & 678 & $1.202 \%$ \\
\hline 10 & Johns Hopkins University & USA & 654 & $1.160 \%$ \\
\hline
\end{tabular}

Regarding language analysis, the results showed that English was the most common language of the publications published and indexed in the WoS database for the COVID19 followed by Spanish, German, and French (Table 4).

Finally, most of the authors worked about this topic were "anonymous authors" $(n=643)$ in analysis of data in WoS database that it means there were many documents without author names and did not mention for their documents any authors. This followed by the authors including "Wang Y" $(n=209)$ and "Zhang Y" $(n=196)$ as shown in the following table (Table 5).

Another analysis in this research was about the hot papers published and determined among all the records extracted about the coronavirus and COVID-19 in our study, all of which had been published in 2020. The hot papers included 309 records. In total, these documents, which were in the form of papers $(n=254)$, reviews $(n=55)$, and early access studies $(n=28)$ had been cited by 106,006 times before writing this paper.

Table 3 The top ten countries collaborated in publishing the documents

\begin{tabular}{llll}
\hline NO & Countries & Record Count & $\%$ of 56,402 \\
\hline 1 & USA & 15,860 & $28.120 \%$ \\
2 & China & 7328 & $12.992 \%$ \\
3 & Italy & 5956 & $10.560 \%$ \\
4 & England & 5646 & $10.010 \%$ \\
5 & India & 3168 & $5.617 \%$ \\
6 & Canada & 2492 & $4.418 \%$ \\
7 & Germany & 2448 & $4.340 \%$ \\
8 & Spain & 2337 & $4.143 \%$ \\
9 & Spain & 2273 & $4.030 \%$ \\
10 & Australia & 2256 & $4.000 \%$ \\
\hline
\end{tabular}

Table 4 The top ten Languages of publications

\begin{tabular}{llll}
\cline { 2 - 3 } publications & English & 53,757 \\
2 & Spanish & 912 \\
3 & German & 604 \\
4 & French & 301 \\
5 & Italian & 214 \\
6 & Portuguese & 195 \\
7 & Russian & 123 \\
8 & Turkish & 61 \\
9 & Norwegian & 60 \\
10 & Hungarian & 57
\end{tabular}

Table 6 shows the top ten hot papers. As shown in Table 6, the top paper with 6947 citations had been indexed in "the Lancet" Journal with an impact factor of 60.392. Most of these ten papers had also been published in "the Lancet" journal $(n=4)$ followed by the "New England Journal of Medicine" $(n=3)$ (Table 6).

All the 309 "hot papers" were also analyzed using VOSviewer and ScientoPy programs and our analysis results were illustrated. Figure 3 shows co-occurrence network mapping of 1082 keywords related to COVID-19 in these documents using the VOSviewer program. The keywords with a frequency of at least 5 times were analyzed. So, 65 keywords of the publications were investigated. Colors represent the groups of keywords that are relatively or strongly related and linked to each other. Size of the node signifies the number of the related documents. In total, 5 clusters were obtained from these keywords (Fig. 3).

Figure 4 shows these keywords in another view using ScientoPy program. This evolution plot shows the accumulative number of documents versus the publication year. The final of each line in the Y-axis represents the number of documents published for each topic. Coronavirus, COVID-19,

Table 5 The top ten authors collaborated in publishing the scientific outputs

\begin{tabular}{lll}
\hline NO & Authors & Record Count \\
\hline 1 & Anonymous & 643 \\
2 & Wang Y & 209 \\
3 & Zhang Y & 196 \\
4 & Wang J & 190 \\
5 & Li Y & 180 \\
6 & Liu Y & 179 \\
7 & Liu J & 167 \\
8 & Li J & 161 \\
9 & Wang L & 158 \\
10 & Zhang L & 143 \\
\hline
\end{tabular}


Table 6. The top ten hot papers

\begin{tabular}{|c|c|c|c|c|c|c|}
\hline NO & Title & $\begin{array}{l}\text { Date of } \\
\text { Publish }\end{array}$ & Authors & Citations & Journal & IF \\
\hline 1 & $\begin{array}{l}\text { Clinical features of patients infected with } 2019 \text { novel } \\
\text { coronavirus in Wuhan, China }\end{array}$ & $\begin{array}{l}\text { FEB } \\
\qquad \begin{array}{l}152- \\
020\end{array}\end{array}$ & $\begin{array}{l}\text { Huang, Chaolin; Wang, } \\
\text { Yeming; Li, Xingwang; } \\
\text { et al. }\end{array}$ & 6947 & Lancet & 60.392 \\
\hline 2 & $\begin{array}{l}\text { Clinical Characteristics of Coronavirus Disease } 2019 \text { in } \\
\text { China }\end{array}$ & $\begin{array}{l}\text { APR } \\
302- \\
020\end{array}$ & $\begin{array}{l}\text { Guan, W.; Ni, Z.; Hu, Yu; } \\
\text { et al. }\end{array}$ & 4441 & $\begin{array}{l}\text { New England Journal } \\
\text { of Medicine }\end{array}$ & 74.699 \\
\hline 3 & $\begin{array}{l}\text { Clinical Characteristics of } 138 \text { Hospitalized Patients With } \\
2019 \text { Novel Coronavirus-Infected Pneumonia in } \\
\text { Wuhan, China }\end{array}$ & $\begin{array}{l}\text { MAR } \\
172- \\
020\end{array}$ & $\begin{array}{l}\text { Wang, Dawei; } \mathrm{Hu}, \mathrm{Bo} ; \mathrm{Hu} \text {, } \\
\text { Chang; et al. }\end{array}$ & 4230 & $\begin{array}{l}\text { JAMA-Journal of The } \\
\text { American Medical } \\
\text { Association }\end{array}$ & 45.54 \\
\hline 4 & $\begin{array}{l}\text { A Novel Coronavirus from Patients with Pneumonia in } \\
\text { China, } 2019\end{array}$ & $\begin{array}{l}\text { FEB } \\
202- \\
020\end{array}$ & $\begin{array}{l}\text { Zhu, Na; Zhang, Dingyu; } \\
\text { Wang, Wenling; et al. } \\
\text { Group Author(s): China Novel } \\
\text { Coronavirus }\end{array}$ & 3773 & $\begin{array}{l}\text { New England Journal } \\
\text { of Medicine }\end{array}$ & 74.699 \\
\hline 5 & $\begin{array}{l}\text { Clinical course and risk factors for mortality of adult } \\
\text { inpatients with COVID-19 in Wuhan, China: a retro- } \\
\text { spective cohort study }\end{array}$ & $\begin{array}{l}\text { MAR } \\
282- \\
020\end{array}$ & $\begin{array}{l}\text { Zhou, Fei; Yu, Ting; Du, } \\
\text { Ronghui; et al. }\end{array}$ & 3744 & Lancet & 60.392 \\
\hline 6 & $\begin{array}{l}\text { Epidemiological and clinical characteristics of } 99 \text { cases of } \\
2019 \text { novel coronavirus pneumonia in Wuhan, China: a } \\
\text { descriptive study }\end{array}$ & $\begin{array}{l}\text { FEB } \\
\qquad \begin{array}{l}152- \\
020\end{array}\end{array}$ & $\begin{array}{l}\text { Chen, Nanshan; Zhou, Min; } \\
\text { Dong, Xuan; et al. }\end{array}$ & 3599 & Lancet & 60.392 \\
\hline 7 & $\begin{array}{l}\text { A pneumonia outbreak associated with a new coronavirus } \\
\text { of probable bat origin }\end{array}$ & $\begin{array}{l}\text { MAR } \\
202- \\
0\end{array}$ & $\begin{array}{l}\text { Zhou, Peng; Yang, Xing-Lou; } \\
\text { Wang, Xian-Guang; et al. }\end{array}$ & 2891 & Nature & 42.778 \\
\hline 8 & $\begin{array}{l}\text { Early Transmission Dynamics in Wuhan, China, of Novel } \\
\text { Coronavirus-Infected Pneumonia }\end{array}$ & $\begin{array}{l}\text { MAR } \\
262- \\
020\end{array}$ & $\begin{array}{l}\text { Li, Qun; Guan, Xuhua; Wu, } \\
\text { Peng; et al. }\end{array}$ & 2466 & $\begin{array}{l}\text { New England Journal } \\
\text { of Medicine }\end{array}$ & 74.699 \\
\hline 9 & $\begin{array}{l}\text { SARS-CoV-2 Cell Entry Depends on ACE2 and } \\
\text { TMPRSS2 and Is Blocked by a Clinically Proven } \\
\text { Protease Inhibitor }\end{array}$ & $\begin{array}{l}\text { APR } \\
162- \\
020\end{array}$ & $\begin{array}{l}\text { Hoffmann, Markus; } \\
\text { Kleine-Weber, Hannah; } \\
\text { Schroeder, Simon; et al. }\end{array}$ & 1987 & Cell & 38,637 \\
\hline 10 & $\begin{array}{l}\text { Genomic characterisation and epidemiology of } 2019 \text { novel } \\
\text { coronavirus: implications for virus origins and receptor } \\
\text { binding }\end{array}$ & $\begin{array}{l}\text { FEB } \\
222- \\
020\end{array}$ & $\begin{array}{l}\text { Lu, Roujian; Zhao, Xiang; Li, } \\
\text { Juan; et al. }\end{array}$ & 1104 & Lancet & 60.392 \\
\hline
\end{tabular}

SARS, and Pneumonia were the most topics used in the retrieved documents (Fig. 4).
Regarding visualization of the co-authors collaborated in publishing these hot papers, among 3226 authors, 55 authors

Fig. 3 Co-occurrence network mapping of the keywords related to COVID-19 in hot papers

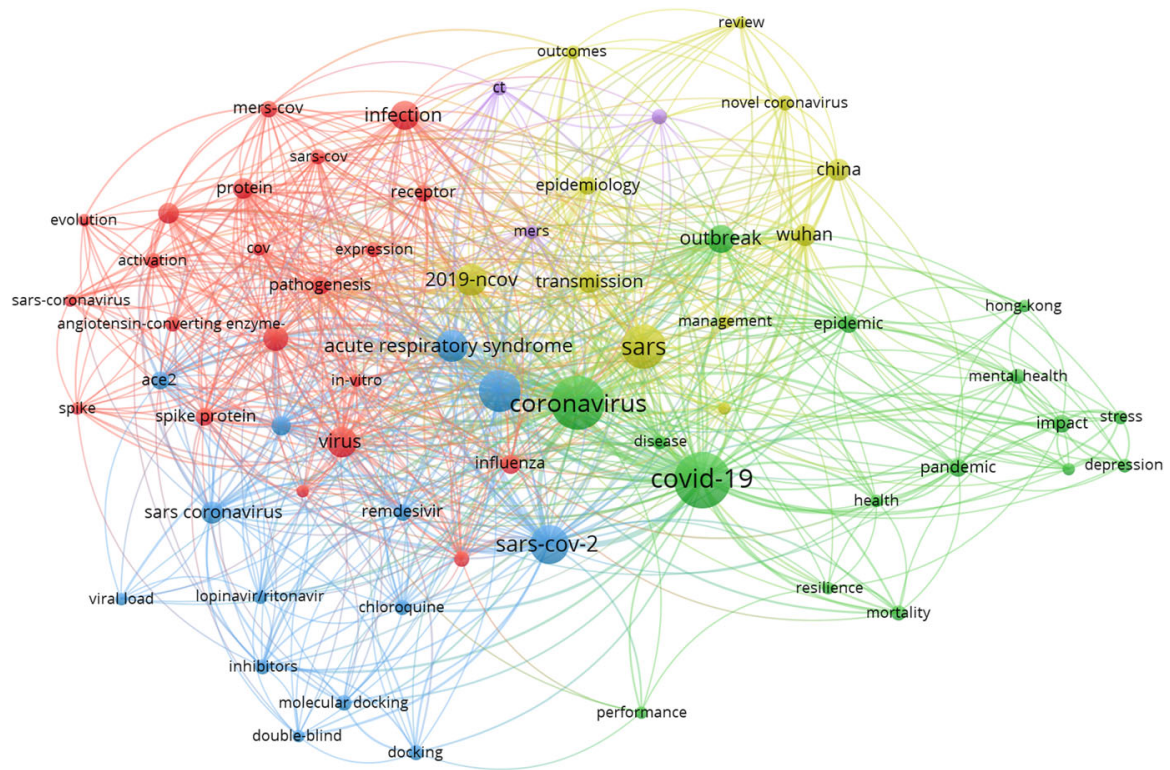


Fig. 4 Twenty-five trending topics of COVID-19 based on the keywords evolution plot

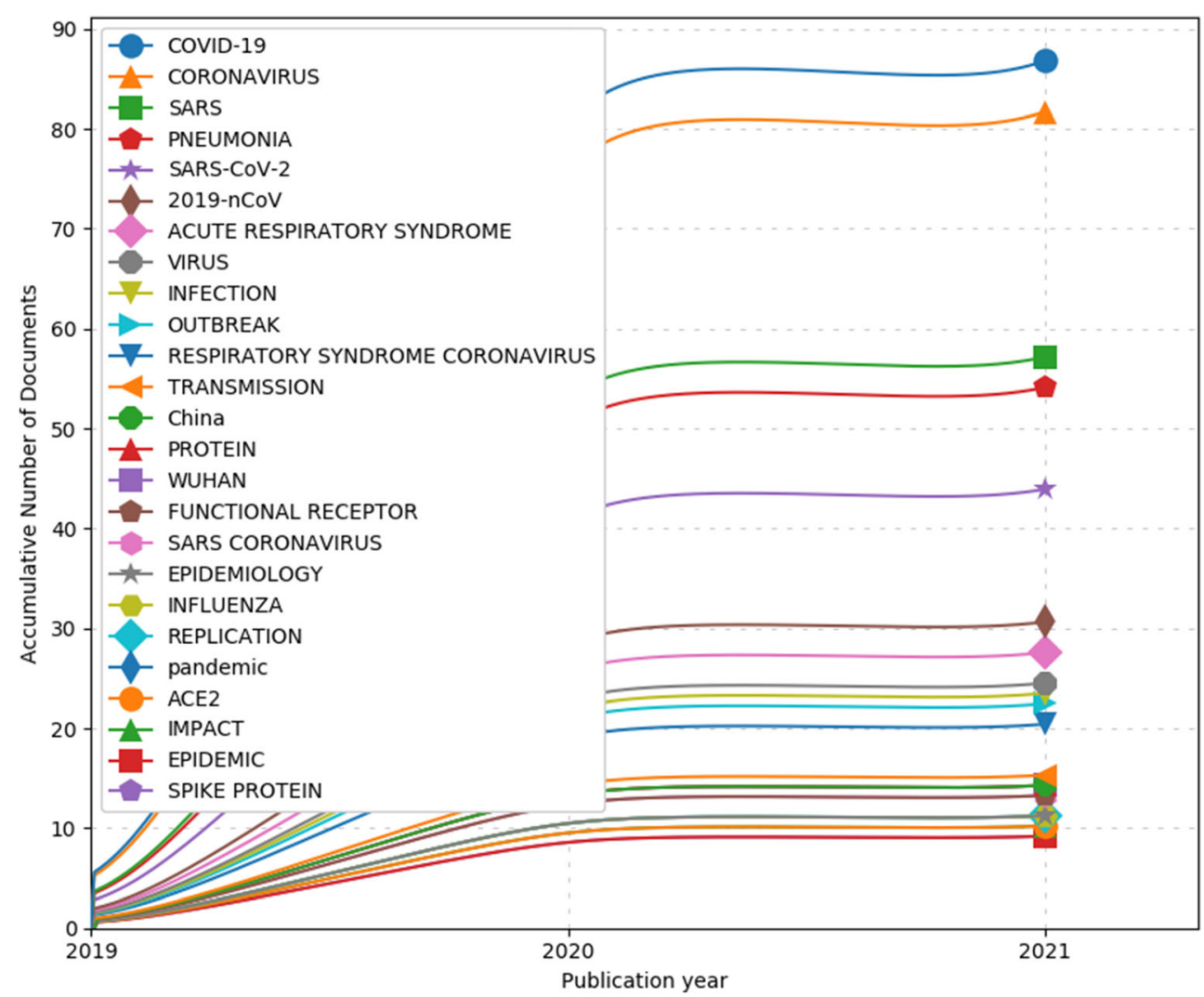

had at least 3 papers as shown in Fig. 5. There are 6 clusters in this figure. Liu, Lei has the most total link strength $(n=30)$ with 5 documents and 1214 citations. Then, Cao, Bin is in the second rank with 4 documents, 11,252 citations, and total link strength of 29. Also, Yang, Yang has the most hot papers $(n=$ $6)$ and $\mathrm{Yu}$, Ting has the most citations $(n=16,075)$ with 5 papers (Fig. 5).

Figure 6 presents collaboration of 34 countries among 63 countries published at least 2 documents related to COVID-
19. According to this figure provided by the VOSviewer program, there were 7 clusters of countries.

The greatest total link strength of co-authorship links with other countries belonged to the USA $(n=148)$ followed by China $(n=143)$, England $(n=124)$, Canada $(n=91)$, and Italy $(n=82)$. In the following figure, USA is in the back of china that both have shown in red color.

Also, among these 34 countries, china was the most productive country in ranking, with 148 documents and had the
Fig. 5 Visualization of coauthorship network of the authors in hot papers

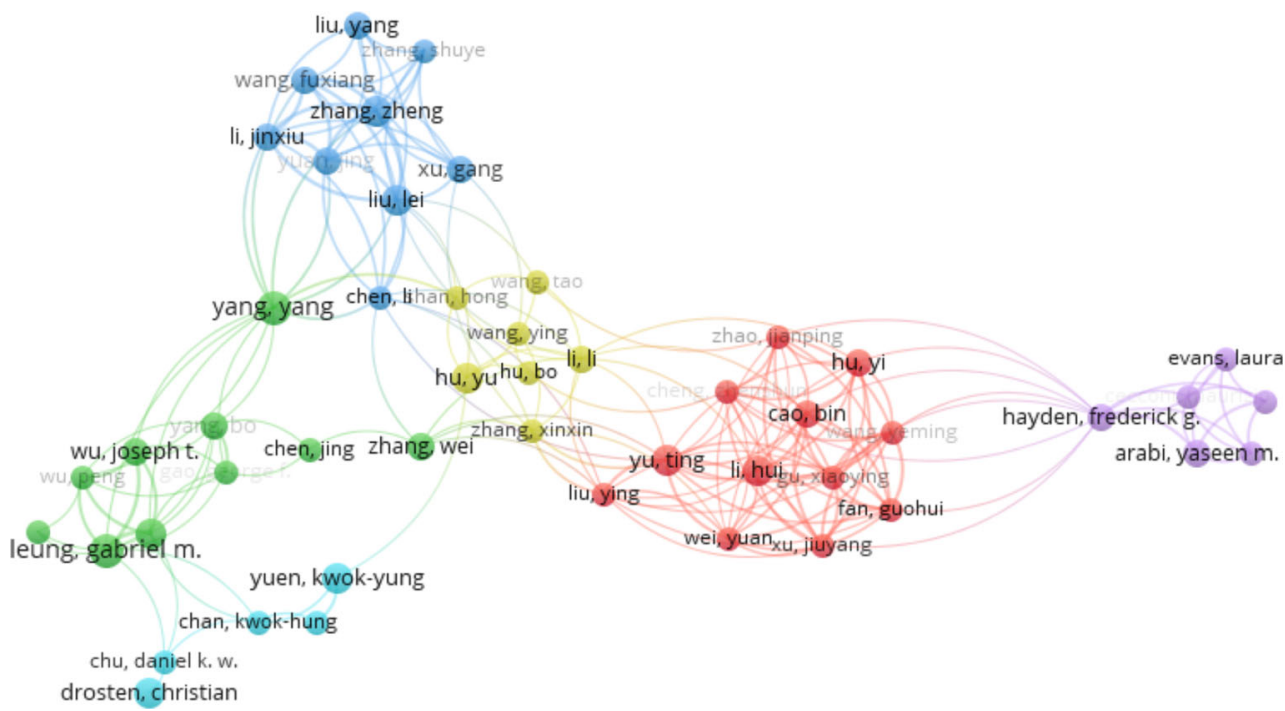


Fig. 6 Visualization of coauthorship network of the countries published hot papers related to COVID-19

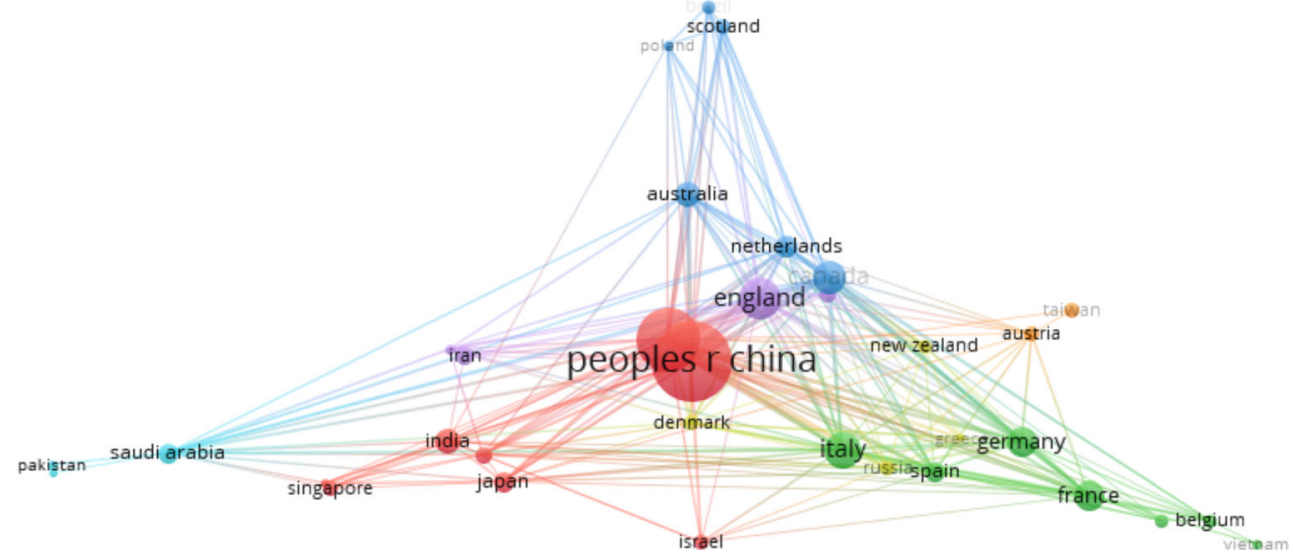

most citations among these countries with 74,800 citations (Fig. 6).

Regarding co-authorship of organizations, among 908 organizations, 38 cases had at least 5 documents 5 clusters of which are presented in Fig. 7. Huazhong University of Science \& Technology with 34 documents and 23,006 citations and the greatest total strength of co-authorship links with other organizations ( $n=53)$ was in top of ranking in terms of publishing documents and link strength. Then, Capital Medical University with 15 documents, 17,341 citations,and total link strength of 44 was in the second rank (Fig. 7).

As shown in Fig. 8 provided by the VOSviewer program, among 155 journals published these 309 documents, 18 journals that had at least 4 hot papers were analyzed and the results of density visualization showed that among these journals, the Lancet $(n=138)$ and New England Journal of Medicine $(n=107)$ had the greatest total strength of citation links with other journals.

The New England Journal of Medicine with 15,454 citations and Journal of Biomolecular Structure and Dynamics with 734 citations, both had the most hot papers $(n=14)$, followed by the Lancet with 11 papers and totally 21,616 citations (as the journal with the most total citations), and both WoS with 3257 citations and International Journal of
Environmental Research and Public Health with 1009 citations that had 8 papers were in the other top ranks(Fig, 8).

Among the hot papers, there were 3 articles in the "Endocrinology Metabolism" category of WoS categories as shown in the following table (updated 24 Nov). These articles were about diabetes mellitus and obesity and published in the journals with the impact factor of greater than 3 (Table 7).

For co-citation analysis of these hot papers in endocrinology category, as shown in the following figure, from 90 cited references, the references with the greatest total link strength has calculated and the references with the most citations also show (Fig. 9).

The 67 cited sources also analyzed in these hot papers in endocrinology category and is shown in the following figure that minimum number of citations of a source, was 1 ciatation. The Lancet $(n=10)$ and New England journal of medicine $(n=7)$ had the most citations respectively (Fig. 10).

\section{Discussion}

In the present paper, a scientometric analysis was performed on all the documents published and indexed in WoS database from the beginning of 2020 up to November 12, 2020. It was
Fig. 7 Network visualization of co-authorship for organizations in publishing the hot papers

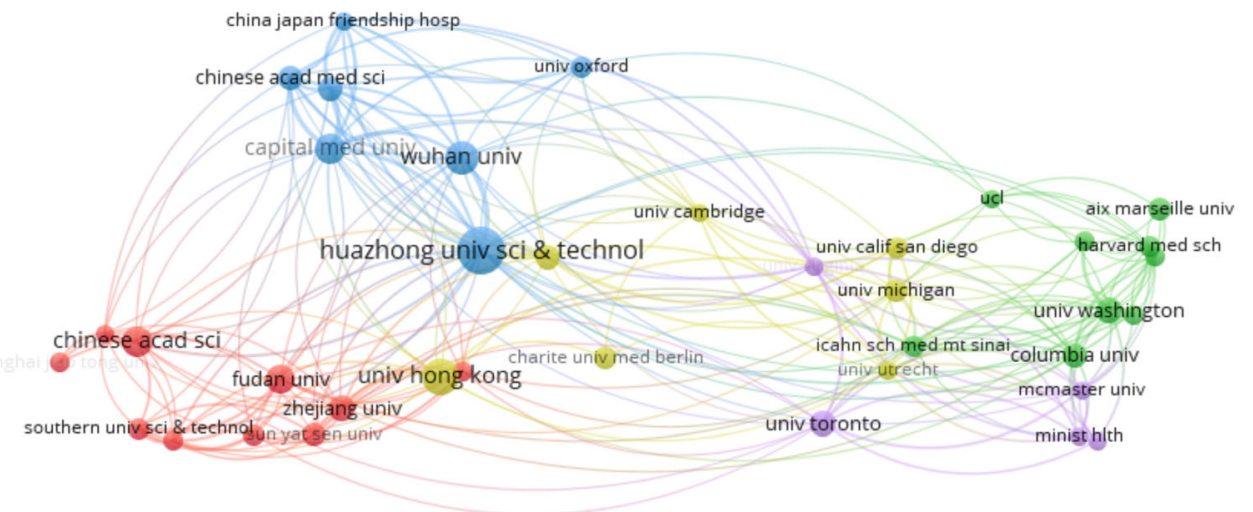




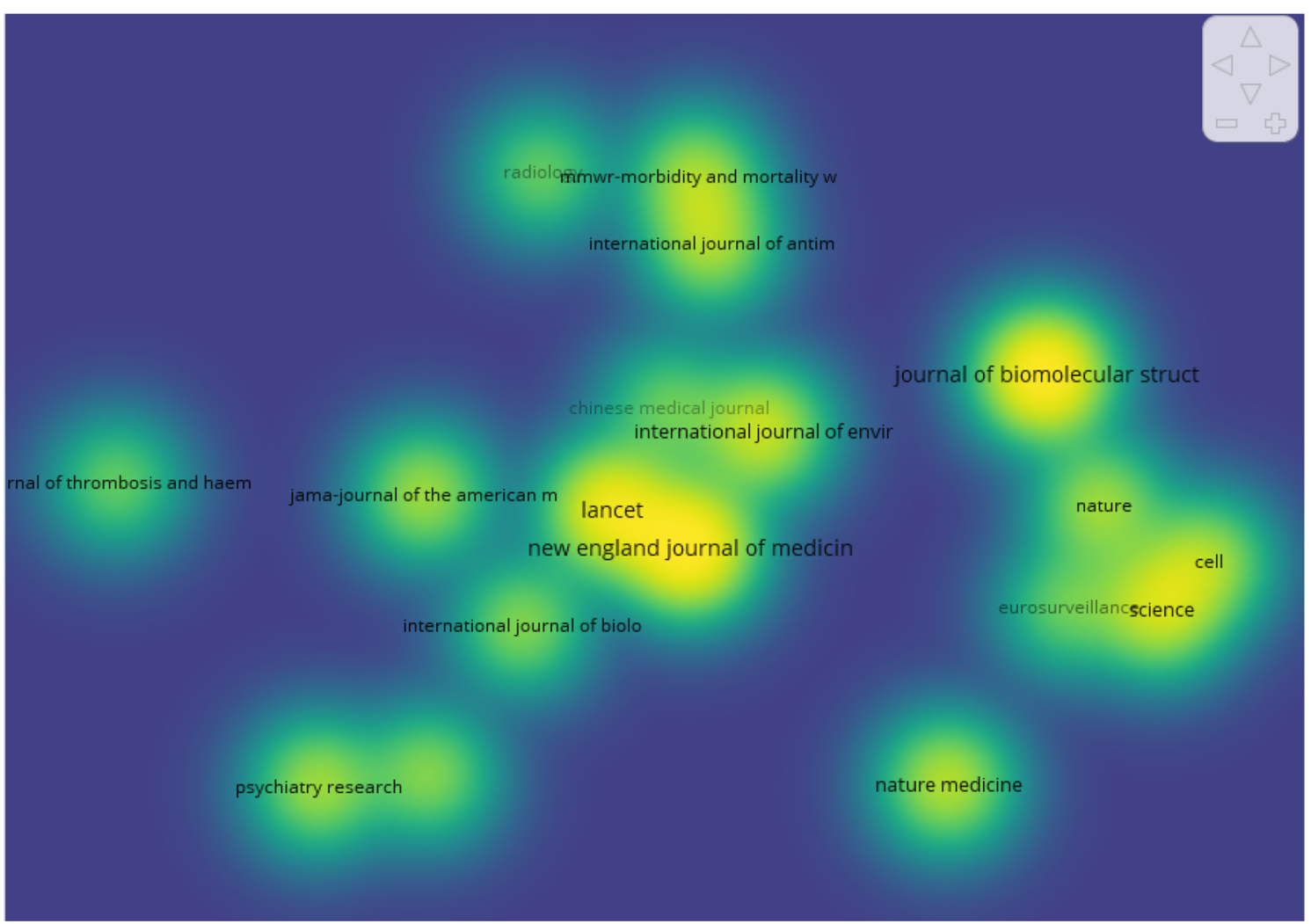

Fig. 8 Density visualization of citation of the journals for hot papers

found out many various research works have been published during the studied time about coronavirus and the number of publications is increased day by day. In this regard, analysis of these publications can be useful and applicable in showing the trends and characteristics of the topic, authors, journals, countries, and activities in this field of medicine and also the attempts in publishing the scientific evidence regarding prevention, control, and treatment of this disease.

Table 7 The hot papers in "Endocrinology Metabolism" category of WoS

\begin{tabular}{|c|c|c|c|c|c|c|c|c|}
\hline NO & Title & $\begin{array}{l}\text { Date of } \\
\text { Publish }\end{array}$ & Authors & countries & Affiliations & Citations & Journal & IF \\
\hline 1 & $\begin{array}{l}\text { High Prevalence of Obesity in } \\
\text { Severe Acute Respiratory } \\
\text { Syndrome Coronavirus-2 } \\
\text { (SARS-CoV-2) Requiring } \\
\text { Invasive Mechanical } \\
\text { Ventilation }\end{array}$ & June 2020 & $\begin{array}{l}\text { Simonnet, } \\
\text { Arthur; } \\
\text { Chetboun, } \\
\text { Mikael; } \\
\text { Poissy, } \\
\text { Julien; } \\
\text { et al. }\end{array}$ & France & $\begin{array}{l}\text { CHU Lille,, Lille, } \\
\text { France } \\
\text { Univ Lille, Lille, } \\
\text { France }\end{array}$ & 307 & Obesity & 3.742 \\
\hline 2 & $\begin{array}{l}\text { Diabetes is a risk factor for the } \\
\text { progression and prognosis of } \\
\text { COVID-19 }\end{array}$ & $\begin{array}{l}\text { April } \\
2020\end{array}$ & $\begin{array}{l}\text { Guo, Weina; } \\
\text { Li, } \\
\text { Mingyue; } \\
\text { Dong, } \\
\text { Yalan; } \\
\text { et al. }\end{array}$ & China & $\begin{array}{l}\text { Huazhong Univ Sci } \\
\text { \& Technol, Union } \\
\text { Hosp, Tongji Med } \\
\text { Coll, Wuhan, } \\
\text { Peoples R China }\end{array}$ & 213 & $\begin{array}{l}\text { Diabetes-Metabolism } \\
\text { Research and Reviews }\end{array}$ & 3.314 \\
\hline 3 & $\begin{array}{l}\text { COVID-19 pandemic, } \\
\text { coronaviruses, and diabetes } \\
\text { mellitus }\end{array}$ & May 2020 & $\begin{array}{l}\text { Muniyappa, } \\
\text { Ranganath; } \\
\text { Gubbi, } \\
\text { Sriram }\end{array}$ & USA & $\begin{array}{l}\text { Natl Inst Diabet \& } \\
\text { Digest \& Kidney } \\
\text { Dis, Clin } \\
\text { Endocrine Sect, } \\
\text { Diabet Endocrinol } \\
\text { \& Obes Branch, } \\
\text { NIH, USA }\end{array}$ & 97 & $\begin{array}{l}\text { American Journal of } \\
\text { Physiology-Endocrinol- } \\
\text { ogy And Metabolism }\end{array}$ & 3.469 \\
\hline
\end{tabular}


Fig. 9 Network visualization for co-citation of cited references

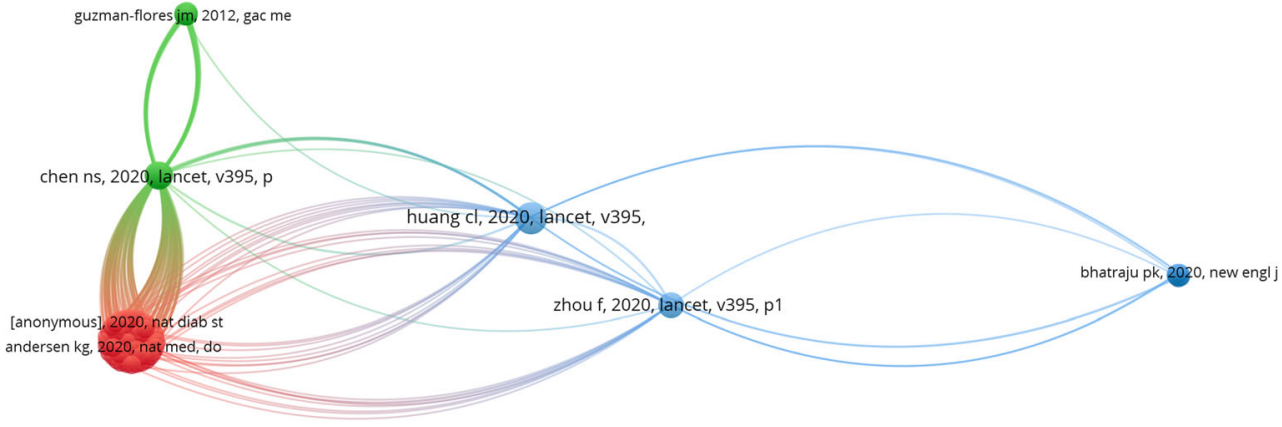

Similarly, there are many studies analyzed these publications in different databases and in the last months such as Dehghanbanadaki et al. [19] Tran et al. [22] and De Felice and Polimeni [23] studies. But this study is a scientometric analysis to analyze the last publications indexed in the WoS database and all the outputs of scientists about this virus in various aspects and to visualize the published hot papers.

Our results showed a lot of documents published and indexed in the WoS database so far. The original papers and editorials accounted for the most publications and there were many other types of documents published related to coronavirus concept. Dehghanbanadaki et al., showed different results in terms of document type and they conducted this study in the last months by searching the Scopus database from December 1, 2019 to April 1, 2020. They retrieved 923 documents on COVID-19 and half of the retrieved documents were original papers followed by the letters with 151 , notes with134, editorials with 116 , and reviews with 75 records [19]. In their study, after the original papers, the letters had the second rank and editorials had the third rank. But in our study, editorials had the second rank and the letter was in the third rank.

Regarding ranking of the countries contributed in publishing the research works related to the coronavirus, the USA was ranked the first followed by China, Italy, and England. Comparing other studies done in the past months, for instance, in the study by Tran et al.,, the USA, China, and European countries were also in similar ranks [22] .

But in the study by Dehghanbanadaki et al., China was ranked as the first country followed by the USA [19]. Also, in another study by De Felice and Polimeni carried out in the Scopus database between December 1, 2019 and April 20, 2020, China was found to publish the majority of papers, followed by the USA, UK, and Italy [23]. In another research, Chahrour et al., searched the PubMed and WHO databases since December 2019 until March 18, 2020, and showed that China published the greatest number of research with $67 \%$ of publications and Asian countries had the highest research activity with $77 \%$ of original publications [18].

These results show that in the most of research works done in the past months, china has had the most publications about coronavirus and COVID-19 concepts, but in our research that is being carried out in the recent period, the USA has the top rank in publishing the documents about this disease. This may be attributed to the largest number of patients in the USA and more outbreaks of coronavirus in this country as a result of which it probably takes further measures and conducts more research for better control of this disease.

Other results of our study were about journal and source titles of the publications. According to our results, the BMJ and then Journal of Medical Virology and International Journal of Environmental Research and Public Health were among the journals with the most published scientific documents about COVID-19. De Felice and Polimeni also showed that in terms of journal ranking, the "BMJ" has published the highest number of papers $(n=129)$ [23] since the beginning of 2020. Another research by Dehghanbanadaki et al., also showed that the journals of Lancet and BMJ (Clinical Research Edition) published the most documents [19].

Dehghanbanadaki et al., also demonstrated that in terms of ranking institutions, the University of Hong Kong and Huazhong University of Science and Technology were ranked the first [19]. However in our research, the Harvard University, the University of London, and the University of California were among the top ranks.

Fig. 10 Network visualization for co-citation of cited sources

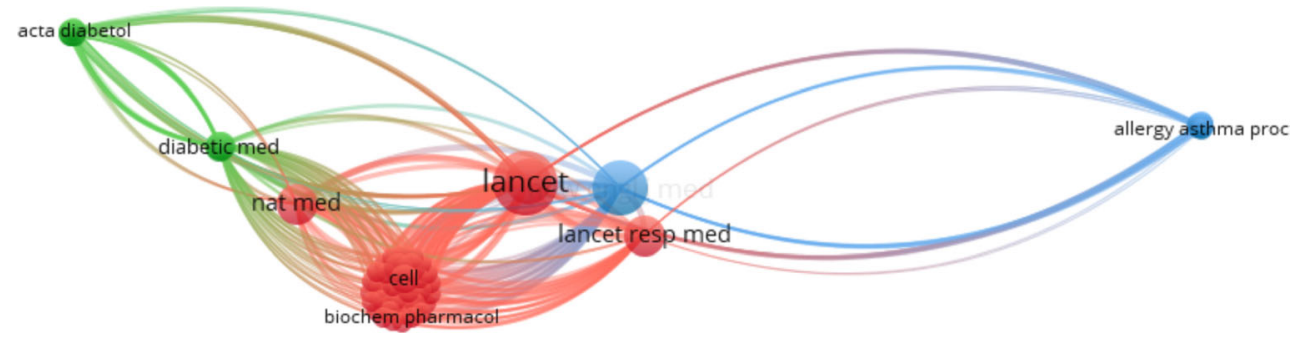


As shown in the literature, although, research works on COVID-19 and coronavirus have generated a large volume of publications and outputs, but there are still the gaps of knowledge to be addressed and there exist the areas to be improved for the global research community and more evidence and analysis of research works are required as well as illustrating all the aspects of scientific publications about this disease [21].

Now the COVID-19 is the disease that can affect all people especially the older people and people with pre-existing medical conditions such as diabetes and they appear to be more vulnerable to becoming severely ill with the this virus [27]. About 422 million people in worldwide have diabetes and the majority of them living in low-and middle-income countries. Also 1.6 million deaths are directly attributed to diabetes each year. Both the number have been steadily increasing over the past few decades [11] and outbreak of COVID-19 affected more and more these people. So more research and analysis of outputs of scientists is very useful in more collaborations to gain the better and faster control of this disease.

Therefore, researchers and organizations should conduct further research and collaborate more in order to find out the gaps in knowledge and to publish their results and aggregate their expertise for control and prevention of this disease and outbreak in the world especially for ensuring less complications for the people with underlying conditions including diabetes, hypertension, obesity, cardiovascular and pulmonary system diseases, cancer, or kidney disease.

\section{Conclusion}

This study was carried out to analyze all the research works published up to now in the WoS database about the coronavirus in many aspects and to illustrate the most important characteristics of highly cited papers retrieved in this study. Our purpose and the strength of this study were determining status and overview of all publishing researches related to coronavirus by researchers and their organizations as well as the research area, the journals, countries, or authors with the most published papers, the types of publications and also details of the published hot papers. These information could be useful to understand the more importance works in this disease and conducting the current or future researches on best topics and gapes in this disease and access the top rank among other articles and publications too. The weakness of our study was that we didn't analyze exclusively all fields and researches area that were related to COVID-19 and we select one category for instance. So carrying out the more researches in other fields and databases also suggested. Furthermore the details of researches and articles and categorizing them in the sub-topic in each field could be useful.
In this study,the results showed that the countries, with the most affected people and patients more attempt to publish research works about coronavirus disease and the literature has a high and fast growth every month, week, day, and also hour. However, there is a need to evaluate these publications once in a while and their results should be published to use this information for more effective management of the future research works and budgets and to focus on important aspects of research and gaps in the science. This would be helpful for prevention, control, and treatment of coronavirus disease that is now among the most common topics in the world.

\section{References}

1. Chen Y, Liu Q, Guo D. Emerging coronaviruses: genome structure, replication, and pathogenesis. J Med Virol. 2020;92(4):418-23.

2. Lu R, Zhao X, Li J, Niu P, Yang B, Wu H, et al. Genomic characterisation and epidemiology of 2019 novel coronavirus: implications for virus origins and receptor binding. Lancet. 2020;395(10224):565-74.

3. Hadi AG, Kadhom M, Hairunisa N, Yousif E, Mohammed SA. A review on COVID-19: origin, spread, symptoms, treatment, and prevention. Biointerface Res Appl Chem. 2020;10:7234-42.

4. Dong E, Du H, Gardner L. An interactive web-based dashboard to track COVID-19 in real time. Lancet Infect Dis. 2020;20(5):533-4.

5. de Haan CA, Rottier PJ. Molecular interactions in the assembly of coronaviruses. Adv Virus Res. 2005;64:165-230.

6. Guo Y-R, Cao Q-D, Hong Z-S, Tan Y-Y, Chen S-D, Jin H-J, et al. The origin, transmission and clinical therapies on coronavirus disease 2019 (COVID-19) outbreak-an update on the status. Military Med Res. 2020;7(1):1-10.

7. Belkacemi Y, Grellier N, Ghith S, Debbi K, Coraggio G, Bounedjar $\mathrm{A}$, et al. A review of the international early recommendations for departments organization and Cancer management priorities during the global COVID-19 pandemic. Applicability in Low-and MiddleIncome Countries. European J Cancer. 2020.

8. Onder G, Rezza G, Brusaferro S. Case-fatality rate and characteristics of patients dying in relation to COVID-19 in Italy. Jama. 2020;323(18):1775-6.

9. Yang X, Yu Y, Xu J, Shu H, Liu H, Wu Y, et al. Clinical course and outcomes of critically ill patients with SARS-CoV-2 pneumonia in Wuhan, China: a single-centered, retrospective, observational study. Lancet Respir Med. 2020;8:475-81.

10. Zhang J-j, Dong X, Cao Y-y, Yuan Y-d, Yang Y-b, Yan Y-q, et al. Clinical characteristics of 140 patients infected with SARS-CoV-2 in Wuhan, China. Allergy. 2020;75(7):1730-1741.

11. WHO. Diabetes: World Health Organization; [cited 16 December 2020]. Available from: https://www.who.int/health-topics/ diabetes\#tab=tab_1.

12. WHO. WHO Health Emergency Dashboard: World Health Organization; 2020 [23 August 2020]. Available from: https:// covid19.who.int/.

13. Motlagh A, Yamrali M, Azghandi S, Azadeh P, Vaezi M, Ashrafi F, et al. COVID19 prevention \& care; a cancer specific guideline. Archives Iranian Med. 2020;23(4):255-64.

14. Park M, Cook AR, Lim JT, Sun Y, Dickens BL. A systematic review of COVID-19 epidemiology based on current evidence. J Clin Med. 2020;9(4):967. 
15. Cortegiani A, Ingoglia G, Ippolito M, Giarratano A, Einav S. A systematic review on the efficacy and safety of chloroquine for the treatment of COVID-19. J Crit Care. 2020.

16. Rodriguez-Morales AJ, Cardona-Ospina JA, Gutiérrez-Ocampo E, Villamizar-Peña R, Holguin-Rivera Y, Escalera-Antezana JP, et al. Clinical, laboratory and imaging features of COVID-19: a systematic review and meta-analysis. Travel Med Infect Dis 2020;34: 101623.

17. Lou J, Tian S-J, Niu S-M, Kang X-Q, Lian H-X, Zhang L-X, et al. Coronavirus disease 2019: a bibliometric analysis and review. Eur Rev Med Pharmacol Sci. 2020;24(6):3411-21.

18. Chahrour M, Assi S, Bejjani M, Nasrallah AA, Salhab H, Fares M, et al. A bibliometric analysis of Covid-19 research activity: A call for increased output. Cureus. 2020;12(3):e7357.

19. Dehghanbanadaki H, Seif F, Vahidi Y, Razi F, Hashemi E, Khoshmirsafa M, et al. Bibliometric analysis of global scientific research on coronavirus (COVID-19). Med J Islamic Republ Iran (MJIRI). 2020;34(1):354-62.

20. Shamsi A, Mansourzadeh MJ, Ghazbani A, Khalagi K, Fahimfar N, Ostovar A. Contribution of Iran in COVID-19 studies: a bibliometrics analysis. J Diabetes Metab Disord 2020:1-10.

21. Liu N, Chee ML, Niu C, Pek PP, Siddiqui FJ, Ansah JP, et al. Coronavirus Disease 2019 (COVID-19): an evidence map of medical literature. medRxiv. 2020;1-10.
22. Tran BX, Ha GH, Nguyen LH, Vu GT, Hoang MT, Le HT, et al. Studies of novel coronavirus disease 19 (COVID-19) pandemic: a global analysis of literature. Int J Environ Res Public Health. 2020;17(11):4095.

23. DE Felice F, Polimeni A. Coronavirus Disease (COVID-19). Machine Learn Bibliometric Analys In Vivo. 2020;34(3 suppl): 1613-7.

24. Purcell LN, Charles AG. An Invited Commentary on World Health Organization declares global emergency: A review of the 2019 novel Coronavirus (COVID-19): Emergency or new reality? Int J Surg (London, England). 2020;76:111.

25. W-j G, Ni Z-y, Hu Y, Liang W-h, Ou C-q, He J-x, et al. Clinical characteristics of coronavirus disease 2019 in China. N Engl J Med. 2020;382(18):1708-20.

26. Rafiei-Nasab F, Rahim F. Bibliometric Analysis of Global Scientific Research on SARSCoV-2 (COVID-19). medRxiv. 2020:1-27. https://doi.org/10.1101/2020.03.19.20038752.

27. IDF. COVID-19 and Diabetes: International Diabetes Federation; [cited 16 December 2020]. Available from: https://www.idf.org/ aboutdiabetes/what-is-diabetes/covid-19-and-diabetes/1-covid-19and-diabetes.html.

Publisher's note Springer Nature remains neutral with regard to jurisdictional claims in published maps and institutional affiliations. 